\title{
Pigments Associated with the Fatty Tissues of Plants and Animals*
}

\author{
By Prof. I. M. Heilbron, F.R.S., and A. E. Gillam.
}

$\mathrm{T}^{\mathrm{H}}$ E fat-soluble pigments (lipochromes) which form the subject of the present survey, comprise a sharply defined class of yellow to violet-red compounds not only widely distributed in flowers and fruits, but also met with throughout the whole of the animal kingdom. In virtue of the fact that the first of these pigments to be obtained in crystalline form was isolated from carrots, they are commonly known as carotenoids. As a group they are characterized further by their insolubility in water, by their sensitivity to atmospheric oxygen, which readily bleaches them, and by the deep blue coloratiun which they give with sulphuric acid. In addition to its occurrence in the carrot, the most typical member of the group, carotene, is invariably found with chlorophyll in all green foliage, being also associated with another yellow consitituent to which the name xanthophyll was originally given. Despite the wide distribution of these two pigments in Nature, it must be emphasized that they, in common with other members of the group, occur only in very minute amounts in living matter. Thus the fresh carrot contains only about $0 \cdot 1$ per cent of carotene, whilst in fresh grass the order approximates only to 0.01 per cent carotene and 0.02 per cent xanthophyll.

Although carotene was originally isolated so early as 1831, the first work of real chemical significance in this field was due to Willstätter and his collaborators who, during the years 190614, effected the isolation of several of the more important carotenoids in crystalline form and established their empirical formulæ. It was thus found that carotene was a hydrocarbon having the formula $\mathrm{C}_{40} \mathrm{H}_{56}$ and that it was isomeric but not identical with lycopene, the pigment of the ripe tomato. Similarly, leaf xanthophyll was shown to have the formula $\mathrm{C}_{40} \mathrm{H}_{56} \mathrm{O}_{2}$ and to be very similar to, if not identical with, the yellow pigment of egg yolk, then known as lutein. Another interesting member characterized at this period was a still more oxygenated pigment, fucoxanthin, $\mathrm{C}_{40} \mathrm{H}_{56} \mathrm{O}_{6}$, which was obtained from Fucus vesiculosus, a member of the brown seaweeds.

The further development of the chemistry of the carotenoids languished until 1928, when Zechmeister, Cholnoky and Vrabely proved, by

* Expanded from a Friday evening discourse at the Royal Institution delivered by Prof. I. M. Heilbron on February 12. means of quantitative catalytic hydrogenation, that carotene contains eleven ethenoid linkages giving rise to a saturated perhydrocarotene of formula $\mathrm{C}_{56} \mathrm{H}_{78}$, from which it can be deduced that the pigment itself must contain two cyclic systems. In a similar manner, Karrer and Widmer ascertained that lycopene absorbs thirteen molecules of hydrogen yielding a paraffin hydrocarbon $\mathrm{C}_{40} \mathrm{H}_{82}$, a result which shows that the pigment must by acyclic.

The next important development in our knowledge of the carotenoids came about when Kuhn, Lederer and Winterstein reintroduced the method of chromatographic analysis, as a means of separating and purifying the individual pigments of plant tissues. So early as 1906, the Russian botanist Tswett had shown that substances such as calcium carbonate or powdered sucrose, when packed in vertical columns, have the power of absorbing pigments from their solutions in nonpolar solvents such as light petroleum, and that with a mixture of pigments the constituents orient themselves as coloured zones or bands at various positions on the column, depending upon the strength of adsorption of the individual components. On applying this technique to ordinary carrot carotene, it was found that the pigment could be separated into two distinct components, the optically inactive $\beta$-carotene and the dextrorotatory $\alpha$-carotene. The former is adsorbed above the latter when the chromatogram is developed by washing with light petroleum. Of these two isomerides, $\beta$-carotene generally predominates, although in palm oil carotene there is as much as thirty per cent of the $\alpha$-isomer.

Shortly after this discovery, the presence of a third isomer, $\gamma$-carotene, was disclosed under conditions which serve to emphasize the elegance of this technique, which more than any other has contributed to the recent rapid progress in this field. Commencing with $35 \mathrm{gm}$. of commercial crystalline carotene (equal to about 6 cwt. of raw carrots) Kuhn and Brockmann subjected it to chromatographic adsorption and observed a small pigmented zone above that of the $\beta$-carotene in the column. After many adsorp. tions they ultimately succeeded in isolating from the collected upper zones $34 \mathrm{mgm}$. of the $\gamma$-isomeride, with which amount they were able to study its physical, chemical and biological properties and so advance a structural formula for the 
compound-a remarkable example of the delicacy of modern chemical technique.

A further interesting and important point in connexion with chromatography is that not only does it provide us with a readily accessible method for the isolation of minute amounts of specific pigments, but it provides in addition a means of differentiating various classes. Thus the hydroxylated carotenoids (or xanthophylls as they are now generally called) are all much more strongly adsorbed than the hydrocarbon pigments; moreover, the degree of adsorbability is proportional to the number of hydroxyl groups.

Another criterion determining the position of adsorption in the column is the number and disposition of unsaturated linkages. This is illustrated by the fact that lycopene, $\gamma$-carotene, $\beta$-carotene and $\alpha$-carotene are retained on the adsorption column in descending order, which corresponds partly with the total number of ethylene linkages in their molecules and partly with the length of the conjugated system. This latter effect is evidenced in the $\beta$ - and $\alpha$-carotenes, both of which contain eleven double bonds. In the former, however, these are all conjugated, whereas in $\alpha$-carotene only ten are so arranged. Table I (due to Winterstein) illustrates these general principles:

$$
\text { TABLE } 1 .
$$

Relative adsorbability OF Vartods Carotenoids from Light PETROLEUM SOLUTION

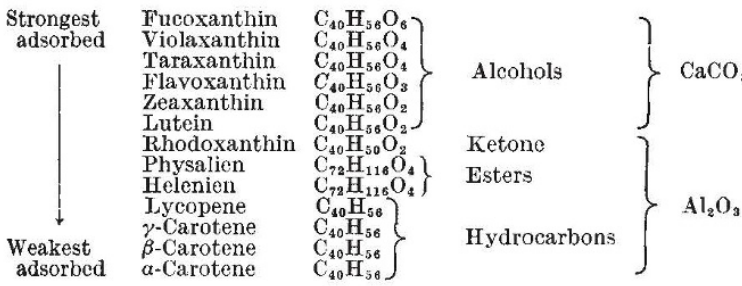

The separation by chromatographic methods alone of a complex mixture of pigments such as is often met with in Nature, is an extremely complicated procedure. Fortunately, however, it can frequently be simplified by carrying out a preliminary partition between two immiscible solvents such as light petroleum and 90 per cent methyl alcohol, when it is found that hydrocarbon pigments and esters pass into the petroleum layer (epiphasic pigments), whilst those pigments containing free hydroxyl groups pass preferentially into the alcohol (hypophasic pigments).

Another physical property of great diagnostic value in the study of carotenoids is that of light absorption. It is a well-established principle that with an increasing number of conjugated unsaturated linkages in a molecule, the absorption maxima become progressively displaced towards longer wave-lengths. This is exceptionally well exemplified among the carotenoids, which are characterized by well-defined triplet absorption bands, and the closest possible correlation exists between the position of the bands and the number and character of the conjugated centres. These effects are shown in Table 2.

TABLE 2

Examples of the Effect of Unsaturation on the absorption SPECTRA OF TYPICAL CAROTENOIDS

Carotenoid. Number of Double Bonds. Absorption maxima in $\mathrm{CS}_{2}(\mathrm{~m} \mu)$ Conjugated Unconjugated

$\begin{array}{lllll}\text { Rhodoxanthin } & \mathbf{1 4}(2 \mathrm{C}=0) & 0 & 564 & \mathbf{5 2 5} \\ \text { Lycopene } & 11 & 2 & 548 & 507 \\ \gamma \text {-Carotene } & 11 & 1 & 533 & 496 \\ \beta \text {-Carotene } & 11 & 0 & 518 & 485 \\ \text { a-Carotene } & 10 & 1 & 508 & 477 \\ \text { Violaxanthin } & 9 & 1 & 501 & 469\end{array}$

It is beyond the scope of this article to attempt to describe in detail the elegant investigations of Karrer, Kuhn, Zechmeister and their respective collaborators, which have culminated in the elucidation of the constitution of these pigments. The formulæ for the four hydrocarbon pigments are given on p. 614, and these represent the fundamental structures upon which a large number of naturally occurring oxygenated derivatives are built.

In Table 3 the hydrocarbons and the simpler xanthophylls which correspond to them are enumerated.

TABLE 3

Relation BETWEeN THE HYDROCARBON CAROTENOIDS AND THE SIMPLER XANTHOPHYLTS

\begin{tabular}{lll} 
Hydrocarbon & $\begin{array}{l}\text { Monohydroxy } \\
\text { Derivative }\end{array}$ & $\begin{array}{l}\text { Dihydroxy } \\
\text { Derivative }\end{array}$ \\
$\mathrm{C}_{40} \mathrm{H}_{56}$ & $\mathrm{C}_{40} \mathrm{H}_{58} \mathrm{O}$ & $\mathrm{C}_{40} \mathrm{H}_{58} \mathrm{O}_{2}$ \\
Lycopene & Lycoxanthin & Lycophyll \\
$\gamma$-Carotene & Rubixanthin & $-\vec{\longrightarrow}$ \\
$\beta$-Carotene & Kryptoxanthin & Zeaxanthin \\
$\alpha$-Carotene & \multicolumn{2}{c}{ Lutein }
\end{tabular}

Of the various possible types of oxygenated carotenoids, alcohols are of most frequent occurrence, and of these it will suffice to mention a few of the more common. Leaf xanthophyll, which consists mainly of a pigment having the formula $\mathrm{C}_{40} \mathrm{H}_{56} \mathrm{O}_{2}$, has been re-named lutein, and is actually a dihydroxy derivative of $\alpha$-carotene, with which it is spectographically identical. The pigment of egg yolk, originally called lutein, has now been separated into lutein proper (leaf xanthophyll) and an isomeric pigment, zeaxanthin. This is a dihydroxy $\beta$-carotene occurring in small quantity in many leaves, berries and fruits, but most readily isolated from maize. The acyclic analogue lycophyll has recently been isolated from several species of Solanum. Of other xanthophylls mention may be made of flavoxanthin $\mathrm{C}_{40} \mathrm{H}_{56} \mathrm{O}_{3}$, the yellow buttercup pigment, violaxanthin $\mathrm{C}_{40} \mathrm{H}_{56} \mathrm{O}_{4}$, the yellow pansy pigment, and the isomeric taraxanthin from the dandelion. 
The pigments so far considered have all been representatives of the higher forms of plant life, but among the Cryptogams, lipochrome pigments also abound, especially among the Algæ. Recent work in this field carried out in the University of Manchester, has brought to light some interesting generalizations. It would seem that whereas carotene is common among all algal orders exactly as in the higher plants, a definite differentiation of

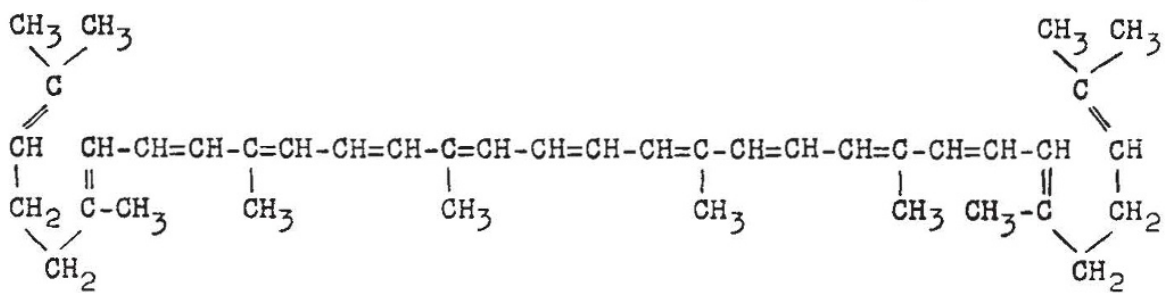

Lycopene

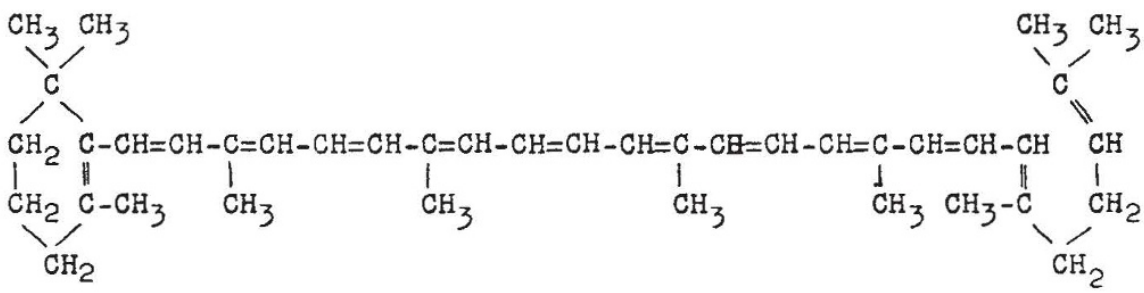

$\gamma$-Carotene

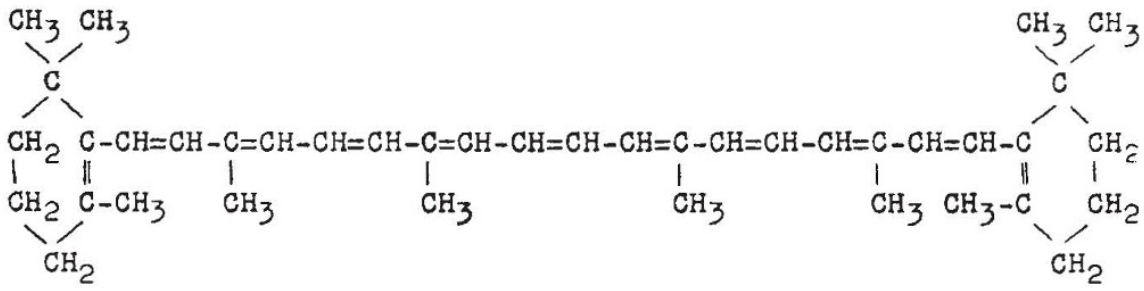

$\beta$-Carotene

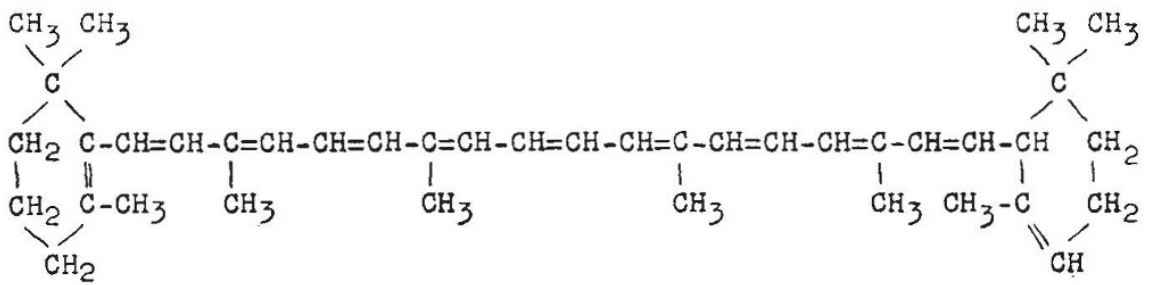

$\alpha \cdot$ Carocien $\theta$

pigment is met with in the various species of Algæ. As examples of this, the Phæophyceæ (brown Algæ) are all characterized by the presence of fucoxanthin, a pigment which is very easily distinguished by the beautiful colour which it gives with 25 per cent hydrochloric acid. Again, among the Cyanophyceæ (blue-green Algæ), a specific pigment, myxoxanthin, is seemingly common to all members of the group.

As already mentioned, the carotenoids are by no means confined to the plant world, but are met with throughout the animal kingdom, from the lowest types of life to man himself. Among the vertebrates, the carotenoids are absorbed from the food and consist therefore mainly of carotene and lutein. Zechmeister and his co-workers have recently made a close study of this subject, and have shown that certain interesting differences are to be observed among the higher animals; thus although the carotenelutein ratio in grass is of the order $1: 2$, both the cow and the horse preferentially absorb carotene to the almost complete exclusion of lutein. Man, on the other hand, evinces no especial preference, and both pigments are found to be present in human blood serum, whilst in the pig, cat, dog and the rodents no carotenoids appear to be retained. The early experiments of Palmer have shown that birds accumulate xanthophylls, to the almost complete exclusion of carotene, in their blood and body-fat as well as in their egg yolk. It has also been shown by Brockmann and Völ. ker that the yellow colour of the plumage of canaries is due to the presence of lutein, or a closely related transformation product, and is produced solely when this pigment is present in the food, for in its absence the feathers become white.

Turning now to the invertebrates, here a great diversity of carotenoids, distinct from those found in plant tissues, are met with. Among the Crustacea, the characteristic bluish colour of the live lobster is due to the presence of a labile chromoprotein, which breaks down at the temperature of boiling water liberating the free lipochrome, astacene. This pigment, which is a tetra-keto$\beta$-carotene, $\mathrm{C}_{40} \mathrm{H}_{56} \mathrm{O}_{4}$, is very widely distributed in aquatic animals, being found in the skin of goldfish, in starfish, in the flesh of salmon, etc.

Among other marine forms, the sea anemones 
also owe their brilliant colours to specific earotenoids of complex character; thus Actinia equina contains a very beautiful purple pigment, actinoerythrin, which is an ester ; the free violerythrin, $\mathrm{C}_{40} \mathrm{H}_{56} \mathrm{O}_{6}$, is characterized by the intense blue colour of its solution in organic solvents. Again, from Anemonia sulcata a still more oxygenated pigment, sulcataxanthin, $\mathrm{C}_{40} \mathrm{H}_{56} \mathrm{O}_{8}$, has been isolated.
Carotenoids have also recently been discovered in bacteria. Thus the purple rhodovibrio bacteria have been shown by Karrer to contain a series of probably six closely related pigments. Of these, rhodoviolascin, $\mathrm{C}_{42} \mathrm{H}_{60} \mathrm{O}_{2}$, has been clearly characterized, and constitutes the first known methylated xanthophyll.

(To be continued.)

\section{The Earthquake Research Institute of Japan}

\section{By Dr. Charles Davison}

$\mathrm{T}$ HE first Japanese earthquake known to us occurred in A.D. 416. For many years, the chronicle of its successors is naturally incomplete, but, with the nineteenth century, the entries become more frequent; how full they are is evident from Omori's studies of the after-shocks of the great earthquakes of 1830,1847 and 1854 . With the Yokohama earthquake of 1880 , the investigation of the earthquakes on modern lines began. Though not of great strength, the shock was the first to arouse the interest of the English professors then living in Tokyo. A few months later, the Seismological Society of Japan was founded by the late Prof. J. Milne, and the admirable work done by him and his colleagues during the next twelve years was continued and expanded by the Imperial Earthquake Investigation Committee and the Earthquake Research Institute.

For the next change, another earthquake was responsible, that of Mino-Owari on October 28, 1891. The widespread damage caused by this great earthquake led to the foundation in the following year of the Imperial Earthquake Investigation Committee, the aims of which were of a practical nature, namely, to discover, if possible, whether the occurrence of earthquakes can be foreseen, and to devise methods of lessening their destructive power. How great was the advance along the second line and how valuable were the contributions of the Committee towards our knowledge of earthquakes in general is clear from the journals that it published and especially from the long series of memoirs that appeared under the name of Prof. F. Omori.

In 1926, shortly after the publication of the valuable reports on the great earthquake of 1923 , the Investigation Committee ceased to exist, and its place was taken by the Earthquake Research Institute, with its home, as before, in the Imperial University of Tokyo. Why the change was made is not quite elear, unless it was felt that the work could be carried on more satisfactorily by younger men. The aim of the new Institute was stated to be scientific research on earthquakes. The first director was Prof. K. Suyehiro, who, on his death in 1932, was succeeded by Prof. M. Ishimoto. In its first year, the staff of the Institute consisted of thirteen members, several of whom had been connected with the Investigation Committee. During the last five years, the number of active members of the Institute was thirty-nine.

When the volumes issued by the Institute are compared with those of its predecessor, two welcome features are manifest-the extraordinary increase in the number of students of pure seismology, and the large number of memoirs written by two or more authors. During the first three years, the new Bulletin appeared twice a year, but in 1929 and after it was issued quarterly. By the end of 1936, fourteen ordinary volumes were completed, as well as three supplementary volumes containing papers and reports on the Sanriku seawaves of 1933, the typhoon of 1934, and the Formosa earthquake of 1935. Altogether, the seventeen volumes include 504 memoirs by ninety authors and number 7,646 pages with 1,023 plates. In the first four volumes, three out of every five papers were written in Japanese with summaries in English or French; but, in the last ten volumes, the ratio, fortunately for Western readers, fell to one in five.

Since the Institute began its work, there have been four great earthquakes in the Japanese empire-those of Tango in 1927, Idu in 1930, Sanriku in 1933 and Formosa in 1935-and, on each of these, series of valuable reports are printed in the Bulletin. Other earthquakes of less, but still destructive, intensity are also described in one or several papers, such as the Etigo earthquake of 1927, the Kaga earthquake of 1930, the Noto earthquake of 1933, the Idu earthquake of 1934, the Siduoka earthquake of 1935 and the KawatiYamato earthquake of 1936 . These are probably the most important Japanese earthquakes of the 